\title{
COMPREENDENDO A CONCEPÇÃO DO CURSO SUPERIOR DE TECNOLOGIA EM ANÁLISE E DESENVOLVIMENTO DE SISTEMAS NO IFPR - CAMPUS IRATI
}

\author{
W. V. Fernandes, ${ }^{1}$ L. R. S. Zontini ${ }^{2}$ e D. D. Zontini ${ }^{3}$ \\ ${ }^{1}$ wesleyviniciusfernandes@gmail.com, ${ }^{2}$ laynara.zontini@ifpr.edu.br, ${ }^{3}$ diego.zontini@ifpr.edu.br \\ Instituto Federal do Paraná - Campus Irati
}

Artigo submetido em novembro/2016 e aceito em dezembro/2016

DOI: $10.15628 /$ rbept.2016.5400

\section{RESUMO}

Esse artigo visa compreender como se deu a concepção do curso superior de Tecnologia em Análise e Desenvolvimento de Sistemas no IFPR - Campus Irati, tendo como objetivo o fortalecimento da sua identidade e historicidade. Utilizando os modos de proceder da pesquisa qualitativa fenomenológica, nos orientamos pela interrogação "Quais argumentos sustentaram a concepção do curso superior de Tecnologia em Análise e Desenvolvimento de Sistemas?". Para isso, fomos ao encontro daqueles que participaram da decisão de abertura do curso, entrevistamos e transcrevemos essas entrevistas, passando a analisar fenomenologicamente os dados produzidos. As convergências dos ditos revelaram o fenômeno por meio de duas categorias: Características Sociopolíticas e Condições do IFPR Campus Irati. Estas foram interpretadas, permitindo-nos compreender o fenômeno investigado. Os resultados da pesquisa mostraram que as orientações legais em relação a infraestrutura e o corpo docente foi um fator decisivo para a abertura especificamente desse curso. Além disso, havia uma expectativa de indução do desenvolvimento local, dada as características regionais que não deixam explícito uma demanda no mercado de trabalho para a Informática.

PALAVRAS-CHAVE: IFPR, Tecnólogo, Análise e Desenvolvimento de Sistemas.

\section{UNDERSTANDING THE CONCEPTION OF THE COURSE OF TECHNOLOGY IN ANALYSIS AND DEVELOPMENT OF COMPUTER SYSTEM IN IFPR - CAMPUS IRATI}

\begin{abstract}
This paper intends to understand how did the conception of the course of Technology in Analysis and Development of Computer Systems in IFPR - Campus Irati, with the objective of strengthening its identity and historicity. Using the methods of qualitative phenomenological research, we orient ourselves by the interrogation "Which arguments supported the conception of the superior course of Technology in Analysis and Development of Computer Systems?". For that, we went to meet those who participated in the decision to open the course, we interviewed and transcribed these interviews, going to analyze the data produced
\end{abstract}

phenomenologically. The convergences of the sayings revealed the phenomenon through two categories: Sociopolitical Characteristics and Conditions of the IFPR Campus Irati. These were interpreted, allowing us to understand the phenomenon investigated. The results of the research showed that legal guidelines about infrastructure and academic staff were a decisive factor for opening of this specific course. In addition, there was an expectation of inducing local development, given the regional characteristics that do not make explicit a demand in the labor market for Informatics.

KEYWORDS: IFPR, Technologist, Analysis and Development of Computer System. 


\section{INTRODUÇÃO}

O Instituto Federal do Paraná (IFPR) foi criado em 2008, sendo uma instituição pública federal voltada para o ensino básico, superior e profissional, vinculada ao Ministério da Educação (MEC) através da Secretaria de Educação Profissional e Tecnológica (SETEC).

Em Irati, o IFPR começou suas atividades em março de 2010, inicialmente como Campus Avançado de Curitiba e ofertando os cursos técnicos subsequentes em Informática, Agroecologia e Produção de Moda e alguns cursos de curta duração.

Em 2013, deixou de ser campus avançado e se consolidou como Campus Irati, iniciando a oferta do curso técnico em Informática integrado ao ensino médio. Nessa época, deixou de ofertar o curso de Produção de Moda, isso se deu por orientação da Reitoria para que o campus Irati trabalhasse com apenas dois eixos temáticos de ensino: Informação e Comunicação e Recursos Naturais, e o curso de Produção de Moda não se enquadrava em nenhum desses eixos.

No ano seguinte, foi a vez de dar início a oferta do curso técnico em Agroecologia integrado ao ensino médio, fazendo com que o subsequente em Agroecologia também deixasse de ser ofertado.

Com os cursos técnicos integrados ao ensino médio se consolidando, começou-se a pensar na oferta de um curso superior, dada que uma das missões do IFPR é a verticalização dos eixos temáticos de ensino, ou seja, a oferta das várias modalidades de ensino dentro de um mesmo eixo. Como existiam dois eixos, nos questionamos os motivos que levaram ao eixo de Informação e Comunicação a se verticalizar para um curso superior antes do eixo de Recursos Naturais, tendo em vista que as características regionais ${ }^{1}$ favorecem um curso superior em Agronomia, por exemplo.

Nesse contexto, a experiência vivida no curso superior de Tecnologia em Análise e Desenvolvimento de Sistemas do IFPR - Campus Irati, como docente e aluno, nos desencadeou uma inquietação sobre a motivação para a abertura especificamente desse curso no campus, como ele foi pensado para a cidade de Irati, uma vez que as principais características da cidade não demostram incentivo para tal.

Diante disso, questionamentos sobre a possibilidade de outros cursos na área da informática, como o bacharelado e até mesmo a licenciatura, causaram novas indagações, que não são fruto de insatisfações, pelo contrário, mas da necessidade de perceber o que motivou a abertura do curso e contribuir no fortalecimento do mesmo.

Assim, partindo da interrogação "Quais argumentos sustentaram a concepção do curso superior de Tecnologia em Análise e Desenvolvimento de Sistemas?", iniciamos a pesquisa aqui apresentada. Entendemos o termo concepção, com base no dicionário online Michaelis, como ato de conceber; criação, projeto, plano; então, essa pesquisa tem como objetivo compreender como se deu essa criação do curso superior no campus, fortalecendo sua historicidade e identidade no Campus Irati.

\footnotetext{
${ }^{1}$ Algumas características regionais de Irati serão explicitadas na sequência do texto.
} 


\section{METODOLOGIA}

Apresentamos aqui os resultados de uma pesquisa qualitativa realizada a partir de uma abordagem fenomenológica. Segundo Paulo; Amaral e Santiago (2010), a fenomenologia busca aquilo que se mostra ao pesquisador, busca a compreensão do objeto, do fenômeno investigado, partindo de uma interrogação norteadora, que evidencia uma incerteza, uma inquietação do pesquisador daquilo que se conhece.

“[...]uma pergunta dirigida a algo que se quer saber. É fruto de uma dúvida, de uma incerteza em relação ao que se conhece ou ao que é tido como dado, como certo. Ou ainda pode ser incerteza em relação ao vivido no cotidiano, quando a organização posta ou os acertos mantidos começam a não fazer sentido. O germe da interrogação está no desconforto sentido." (BICUDO apud PAULO; AMARAL e SANTIAGO, 2010, p. 73).

A partir da interrogação: "Quais argumentos sustentaram a concepção do curso Superior de Tecnologia em Análise e Desenvolvimento de Sistemas?", buscamos resgatar o movimento de concepção desse curso, questionando possibilidades de outros cursos, motivos de abertura de um curso superior, aspectos legais do IFPR e também características específicas da cidade de Irati e da região. Tais inquietações só poderiam ser respondidas pelo olhar daqueles que participaram desse processo, que tiveram a oportunidade de tomar as decisões e encaminhar a abertura do curso. Desse modo fomos ao encontro daqueles que participaram da decisão de abertura do curso e, portanto, puderam argumentar para tal, e produzimos os dados através de entrevistas com os docentes, sendo dois da área da informática e dois de outras áreas que participaram da concepção do curso, na época em cargos de gestão no campus Irati.

Não temos aqui o interesse de expor os docentes, por isso optamos por não os nomear preservando a identidade dos depoentes e tendo como foco apenas aquilo que foi dito por eles. De qualquer forma, todos os envolvidos deram ciência e consentimento para o uso de suas falas na pesquisa aqui encaminhada.

As entrevistas foram gravadas e transcritas. E a partir das transcrições, seguimos na redução fenomenológica, realizando a análise ideográfica. Esta etapa consistiu em buscar nas falas ideias centrais que tratem do fenômeno investigado relacionadas a interrogação, tal fenômeno expressado pelo dito dos sujeitos, visando compreender o sentido do todo percebido.

Destacamos fragmentos nas falas, com a intencionalidade característica do método fenomenológico, que nos levaram a Unidades de Significado, definidas por Rojas; Fonseca e Souza (2010, p. 5) como "unidades da descrição que fazem sentido para o pesquisador a partir da interrogação formulada". Então, interpretamos e analisamos o dito de cada entrevistado, considerando todo o contexto e o sentido do discurso exposto. De acordo com Paulo; Amaral e Santiago (2010, p.74), "nessa fase, o pesquisador realiza uma hermenêutica, buscando explicitar o que compreende do dito pelo sujeito, construindo as asserções articuladas ou, colocando na linguagem do pesquisador, o sentido percebido nos discursos do sujeito". 
As Unidades de Significado evidenciam as ideias centrais do fenômeno investigado. Assim, o movimento de redução segue pelas convergências das dez ideias centrais encontradas, tal como podemos visualizar na Figura 1:

Figura1: Convergências das ideias centrais destacadas nos discursos

1. Mercado de trabalho.

2. Característica da cidade.

3. Característica do curso.

4. Interesse político.

5. Eixos temáticos de ensino.

6. Corpo docente.

7. Experiência com o subsequente.

8. Infraestrutura.

9. Aspectos legais.

10. Potencialidades do curso.

Condições do IFPR - Campus

Irati

Ao buscar pelas convergências entre as ideias buscamos por generalidades que tratem do fenômeno, realizando assim a análise nomotética. Nesta análise, mudamos o foco de uma análise individual para uma análise geral, "procurando os aspectos que lhe são significativos nos discursos dos sujeitos e lhe permitem realizar convergências que agregam pontos de vista, modos de dizer, perspectivas, que o levam à compreensão do investigado" (PAULO; AMARAL e SANTIAGO, 2010, p. 74).

Com as convergências chegamos a duas Categorias Abertas: Características Sociopolíticas e Condições do IFPR - Campus Irati. Essas categorias revelam "os resultados de toda a ação do investigador na prática da redução fenomenológica, constituindo-se em subsídios para a análise" (ROJAS; FONSECA e SOUZA, 2010, p. 5).

Após a definição das categorias abertas, passamos à interpretação delas, o que permite "ao investigador explicitar a essência do fenômeno investigado e procura estabelecer resposta para a indagação realizada na pesquisa" (ROJAS; FONSECA e SOUZA 2010, p. 5). Nessa interpretação, buscamos firmar um diálogo entre o dito dos depoentes e a bibliografia levantada, possibilitando reflexões pertinentes ao fenômeno investigado.

Na sequência apresentamos as reflexões de cada categoria na busca por explicitar aquilo que é próprio de cada uma, mesmo cientes de que elas não se dão de forma totalmente disjuntas, mas se entrelaçam permitindo a compreensão do todo. 


\section{CARACTERÍSTICAS SOCIOPOLÍTICAS}

As Características Sociopolíticas de Irati se destacaram como categoria através da convergência das ideias centrais relacionadas ao mercado de trabalho, característica da cidade, interesse político, aspectos legais e potencialidades do curso. Tais ideias revelam as particularidades do arranjo produtivo local e sua relação direta com a concepção do curso superior em Tecnologia em Análise e Desenvolvimento de Sistemas do IFPR - Campus Irati.

O termo sociopolítico significa, segundo o dicionário online de Língua Portuguesa Michaelis, algo que possui elementos sociais e políticos simultaneamente. Assim, entendemos essas características sociopolíticas como as peculiaridades inerentes aos aspectos sociais e políticos de Irati.

Segundo o IPARDES (Instituto Paranaense de Desenvolvimento Econômico e Social), o município de Irati possui uma área total de $995,289 \mathrm{~km}^{2}$, localizado a uma distância de média da capital de 150,34 km, na chamada Mesorregião Sudeste Paranaense. Essa Mesorregião é composta por 21 municípios, predominantemente rurais e caracterizada por possuir "as maiores áreas de florestas naturais do Paraná, com grandes reservas de araucária e de erva-mate, tendo a exploração de ambas se constituído historicamente na base econômica regional" (IRATI, 2010).

Nesse contexto, uma das primeiras ideias surgidas com a análise ideográfica ressalta que houve um interesse político para a implantação de um campus do IFPR em Irati. As lideranças políticas do município se esforçaram para que isso acontecesse, através de doações de terrenos para a instalação do campus, como observamos nas falas:

\section{P1:" [...] em 2009 começou uma negociação para ter o campus do instituto em Irati."}

$P 1$ : "As lideranças municipais e deputados lutaram para que isso acontecesse."

P1: "O prefeito comprou esse terreno [...]"

Esse esforço político estava relacionado a um interesse em impulsionar o crescimento econômico de Irati, e corroborando com o foco dos Institutos Federais, buscar através do conhecimento científico adquirido pelos egressos dar suporte ao desenvolvimento dos arranjos produtivos locais.

\footnotetext{
"O foco dos institutos federais é a promoção da justiça social, da equidade, do desenvolvimento sustentável com vistas a inclusão social, bem como a busca de soluções técnicas e geração de novas tecnologias. Estas instituições devem responder, de forma ágil e eficaz, às demandas crescentes por formação profissional, por difusão de conhecimentos científicos e de suporte aos arranjos produtivos locais." (SILVA, 2009, p. 8).
}

De acordo com o Plano Diretor Municipal, o município de Irati possui uma importância como centro urbano para os municípios vizinhos, devido a sua localização geográfica estar em uma posição estratégica entre centros urbanos de destaque como Guarapuava, Ponta Grossa e União da Vitória. Com a implantação do IFPR, Irati poderia consolidar ainda mais tal importância, dando margem para um reconhecimento econômico dessa Mesorregião do interior do Paraná, tal como destaca a fala seguinte:

P2: "[...] colocar o interior, tirar o interior da periferia e o fato de o instituto vir para uma região de interior [...]" 
Conforme dados do IPARDES, ressaltados pelo Projeto Pedagógico de Curso (PPC), a economia iratiense possui $69 \%$ do PIB baseada no setor de Serviços, $20 \%$ no setor Industrial e $11 \%$ no setor Agropecuário. Levando em consideração a economia numa escala regional, a Sudeste detém uma das menores taxas no valor adicionado do Estado, que segundo o Plano Diretor Municipal, é de $2,7 \%$.

Diante disso, percebemos as características particulares de Irati e da região, pautadas nos chamados arranjos produtivos locais, que são definidos como:

"[...] uma forma de aglomeração produtiva de empresas produtoras de bens e serviços afins, que são favorecidas por políticas e ações dos poderes públicos e privados, instituições de pesquisa e centros de tecnologia, e destacam-se por sua capacidade de geração de empregos." (MARTINS; SOUZA e MAIA, 2011, p.2).

O arranjo produtivo local de Irati e da região é apoiado pela AMCESPAR (Associação dos Municípios da Região Sul do Estado do Paraná), que segundo a própria entidade tem a finalidade de fazer uma "integração administrativa, executiva, econômica e social dos municípios que a compõem, compreendidos na região centro-sul do Estado do Paraná". Essa associação, com sede em Irati, também é composta pelos municípios de Fernandes Pinheiro, Guamiranga, Imbituva, Inácio Martins, Mallet, Prudentópolis, Rebouças, Rio Azul e Teixeira Soares e, entre outros objetivos, busca estimular a economia da região, utilizando a mão-de-obra e as matérias-primas locais.

A mesorregião possui um setor industrial ligado ao extrativismo florestal bastante consolidado, estando, conforme o Plano Diretor Municipal aponta, entre as áreas madeireiras mais importantes do Paraná com um valor adicionado de 13,6\%. Com base nesses dados, verificamos que o arranjo produtivo local tem no setor industrial madeireiro uma fonte muito grande para geração de empregos na maioria dos municípios, apoiados pela AMCESPAR.

Os dados econômicos do Plano Diretor Municipal nos revelam que nas atividades agropecuárias o destaque está na produção de feijão, arroz e batata, totalizando $17,6 \%$ da produção estadual. Além disso, o cultivo do fumo na Mesorregião representa $57,2 \%$ da área colhida no Paraná.

“[...] o desempenho positivo das atividades agropecuárias tem sido acompanhado de paralela expansão das industriais, sobretudo em anos recentes, o que evidencia a ligação estreita entre ambas e o peso da transformação de produtos silviagropastorís no âmbito do setor secundário.“(IRATI, 2010, p.70)

Devido as características rurais da maioria dos municípios da Mesorregião Sudeste, o setor de serviços ganha destaque apenas nos centros urbanos, como Irati, conforme já foi apontado. Assim, percebemos que a região não é explicitamente um polo de tecnologia para suprir uma demanda de um curso superior de Tecnologia em Análise e Desenvolvimento de Sistemas, muito pelo contrário, deixa explícito uma tendência maior a cursos em áreas de ciências agrárias e ambientais. Entretanto, pelo porte do município a oferta dos cursos de Engenharia Florestal, Engenharia Ambiental e Geografia pela Unicentro (Universidade Estadual do Centro-Oeste) no município, inviabilizam a abertura dos mesmos no IFPR Campus Irati.

Observando os discursos, notamos que não houve uma pesquisa aprofundada para verificar se existe essa demanda por um curso superior em informática na região:

P2: "[...] mas foi feita uma pesquisa aprofundada não, foi uma pesquisa bem geral, de empresas que usam sistemas [...]" 
P2: "[...] não houve uma pesquisa se de fato existia uma demanda, a quantidade, a proporção, até para pensar a durabilidade do curso."

P3: "[... ] não lembro de ter feito propriamente o levantamento desses dados."

P3: "[...] esse levantamento, anteriormente, para verificar se havia campo de trabalho e como que era essa questão de inserção no mercado, não sei responder."

Mesmo que não haja uma inserção no mercado de trabalho de Irati e da região, um entrevistado ressaltou o conceito de indução regional:

P1: "[...] a gente acredita numa questão que não seria vocação regional e sim indução regional $[\ldots] "$

De acordo com esse conceito, a cidade poderia atrair empresas ligadas a tecnologia, desde que pudesse absorver uma mão-de-obra local qualificada, que seria a mão-de-obra formada por curso superior em informática do IFPR.

\begin{abstract}
"De qualquer forma, as regiões atrasadas só alcançarão o desenvolvimento econômico a partir do momento que os empreendedores decidirem buscar por ele. Sendo assim, não adianta apenas determinação, mas sim uma visão real do que é necessário fazer para que o desenvolvimento aconteça, sendo que esta visão só ocorre à medida que o processo de desenvolvimento acontece."(WILLERS apud SORGI, 2009, p. 17).
\end{abstract}

Como nos mostra a referência, a indução regional também pode estar relacionada com o empreendedorismo, já que os próprios profissionais qualificados podem buscar desenvolver uma região economicamente através da criação de novas empresas.

Então, as características sociopolíticas se mostraram como extremamente importante para a concepção do curso superior de Tecnologia em Análise e Desenvolvimento de Sistemas, tendo em vista que o arranjo produtivo local dá margem para um curso superior relacionado aos recursos naturais, mas que encontram nas Condições do IFPR - Campus Irati uma barreira para sua efetivação.

\title{
4 CONDIÇÕES DO IFPR - CAMPUS IRATI
}

As condições do IFPR - Campus Irati apresentaram-se como categoria através de ideias centrais explicitadas por todos os entrevistados. Tais ideias ressaltam as características do curso, os eixos temáticos de ensino, o corpo docente e a infraestrutura existente, a experiência com o subsequente e os aspectos legais que regem os Institutos Federais, servindo de argumentos para a implantação do curso superior de Tecnologia em Análise e Desenvolvimento de Sistemas do IFPR - Campus Irati. Diante disso, as condições do campus Irati são de suma importância para o desenvolvimento dessa pesquisa.

Conforme o dicionário online de Língua Portuguesa Michaelis, o termo condição significa: estado, modo de ser (das coisas); requisito para que outra coisa seja feita ou entre vigor; circunstância indispensável para um resultado. Assim, entendemos como condição aquilo que é necessário para a existência de algo, um requisito que possibilita um resultado.

Dessa forma, as ideias centrais que convergiram nessa categoria revelam os requisitos necessários para a concepção de um curso superior no IFPR - Campus Irati, cujo argumento principal se baseia na lei 11.892, de 29/12/2008 que instituiu a Rede Federal de Educação Profissional, Científica e Tecnológica. 
“[...] cada instituto deverá garantir o mínimo de 50\% (cinquenta por cento) destas para atender a educação profissional técnica de nível médio, priorizando a forma de oferta integrada ao ensino médio [...] estabelece um percentual mínimo de $20 \%$ (vinte por cento) para cursos de licenciatura, programas especiais de formação pedagógica com vistas a formação de professores para a educação básica [...]“ (SILVA, 2009, p. 46)

Segundo essa referência, o Instituto Federal do Paraná como um todo, considerando todos os campi, possuem uma porcentagem mínima de vagas a serem ofertadas em cada modalidade de ensino, entretanto percebemos uma interpretação divergente dessa lei por um entrevistado:

P1: "[...] que a lei diz o seguinte, $50 \%$ das vagas que campus tem que ofertar é para os cursos técnicos de nível médio, então para lei, agroecologia e informática de nível médio, aí 30\% dos cursos, das vagas tem que ser ofertadas em outra modalidade e $20 \%$ de licenciatura."

O que fica evidente nesse ponto é um interesse muito grande por parte da reitoria que o campus ofertasse um curso superior:

P1: "[...] Pró-Reitoria de ensino fazia uma exigência disso [...]" $[\ldots]^{\prime \prime}$

P2: "[...] tínhamos também uma proposta da própria reitoria de pensar num curso tecnólogo

P3: "[...] dentro das missões do IF e da proposta do IFPR, há a questão da verticalização dos cursos $[\ldots] "$

A questão da verticalização está relacionada aos chamados eixos temáticos de ensino, onde o campus deve ofertar as diversas modalidades de ensino dentro do seu respectivo eixo temático:

“[...] é da natureza dos institutos federais validar a verticalização do ensino e balizar as suas políticas de atuação pela oferta de diferentes níveis e modalidades da educação profissional e tecnológica, básica e superior [...]" (SILVIA, 2009, p. 24-25)

No caso de Irati, o IFPR estabeleceu que o campus deveria trabalhar com dois eixos temáticos de ensino: Recursos Naturais e Informação e Comunicação. Na época, já estava ocorrendo a oferta nos dois eixos do ensino técnico em integrado ao ensino médio e a procura pelo ensino técnico subsequente havia diminuído, por isso, a verticalização para o ensino superior começou a ser pensada.

Entretanto, o IFPR - Campus Irati precisava atender várias condições para comportar um curso superior como está estabelecido no decreto № 5.773, de 9 de maio de 2006, onde a instituição deve possuir infraestrutura física, corpo docente capacitado, entre outros requisitos burocráticos para o funcionamento de um curso de graduação.

A questão da infraestrutura e do corpo docente foi um fator decisivo na hora de optar por qual dos eixos temáticos de ensino seria verticalizado, uma vez que os cursos técnicos de agroecologia e informática integrados ao ensino médio já estavam sendo ofertados. Conforme as falas, entre outros motivos que levaram a informática a se verticalizar primeiro estava a infraestrutura física que o campus já possuía devido ao histórico com o curso técnico subsequente, bem como o corpo docente suficiente para suprir a demanda de um curso superior na área, enquanto que a agroecologia necessitava de laboratórios, terrenos para aulas práticas e estava com um corpo docente limitado.

P1: "[...] uma das questões que se levou a informática e não a agroecologia foi a questão do curso, como a estrutura do curso, a gente já tinha uma estrutura de laboratórios e professores." 
P1: "Pegar a estrutura, aproveitar a estrutura tanto de professores técnicos, assim como laboratórios [...]"

P2: "[...] precisa se preocupar com questão externa, de terrenos, principalmente na área de agroecologia se fosse se pensar na época, e como os professores estavam finalizando a proposta de um curso integrado de agroecologia com o ensino médio [...]"

P2: "[...] houve essa necessidade de pensar essa verticalização do eixo de informática [...]"

P2: "[...] o de informática já estava mais consolidado por que já estava com uma turma de integrado, aí houve, então, essa iniciativa dos próprios professores de informática junto com a direção geral, a direção de ensino da época, para que verticalizasse em termos de curso superior."

A partir de então, nasceu toda uma discussão acerca de qual modalidade de curso superior seria ofertada: bacharelado, licenciatura ou tecnólogo.

P2: "Uma das primeiras preocupações foi, vamos abrir um curso de licenciatura em informática ou um curso de graduação, bacharelado, 4 anos, integral ou vamos realmente abrir um tecnólogo no início [...]"

Entre os argumentos explicitados pelas entrevistas em relação a licenciatura, destaca-se:

P2: "[...] a licenciatura, só tinha dois professores formados em licenciatura, não é a demanda da região [...]"

Na Tabela 1 podemos observar a formação dos docentes membros do Núcleo Docente Estruturante do curso superior de Tecnologia em Análise e Desenvolvimento de Sistemas, encontrados no Projeto Pedagógico do Curso (PPC).

Tabela 1: Área de formação dos docentes membros do Núcleo Estruturante do curso.

\begin{tabular}{c|c}
\hline Formação & Quantidade de docentes \\
\hline Licenciatura em Informática & 2 \\
Bacharelado em Informática & 2 \\
Tecnólogo em Informática & 1 \\
Outras licenciaturas & 3 \\
\hline
\end{tabular}

Notamos que o número de docentes de outras licenciaturas, no caso Filosofia, Letras e História, sobressai ao número de docentes com uma formação específica em informática, portanto percebemos que havia um interesse maior em ofertar um curso superior em informática que não fosse licenciatura, já que a oferta de uma licenciatura envolveria demais professores licenciados do campus, conforme notamos na fala:

P1: "[...] ainda não poder ter um curso de licenciatura porque ainda existe uma conversa com os outros professores."

Diante disso, as características do bacharelado e do tecnólogo foram consideradas atreladas as condições do Campus Irati:

P2: "[...] a ciência da computação foi outra proposta levantada por um dos integrantes da equipe de informática, era muito desafiador para a época, exigia muitos docentes e uma infraestrutura que a gente não possuía na época." 
P3: "[...] nós temos que fazer uma otimização de carga horária dos professores."

P3: "[...] se você faz um curso de 4 anos ou 5 anos, você tem uma carga horária maior de professores do núcleo de informática, que sempre vai estar relacionado também ao integrado."

P4: "A gente teve reuniões, levantou debates e durante essas reuniões a gente levantou as várias requisições, o que precisaria para abrir o curso [...]"

P4: "[...] se fosse para um bacharelado, eu preciso de um número de professores doutores já, no programa já enquadrado, existe uma série de demandas legais que precisavam ser atendidas, né?"

Perante os argumentos explicitados pelos entrevistados sobre uma possível abertura de um curso superior de bacharelado em informática, pensou-se que o tecnólogo seria a solução mais viável no momento devido ao fato de que o bacharelado exigiria uma carga horária mínima de 3000 horas prevista no Parecer CNE/CES no 2/2007, enquanto que o tecnólogo exigiria uma carga horária mínima de 2000 horas, de acordo com o Catálogo Nacional de Cursos Superiores de Tecnologia recomendado pelo Ministério da Educação.

Além disso, também foi levado em consideração o fato de que outros campi do IFPR não ofertavam o bacharelado em informática, exceto o Campus Palmas, acreditando-se que o tecnólogo teria mais facilidade para aprovação.

P2: "[...] é um curso mais barato, mais rápido, é um curso que os professores tinham condições de levar [...]"

P3: "[...] foi feita uma busca dentro dos outros IFPRs, o que já tinha sido proposto [...]"

P3: "[...] não havia nos outros IFs nenhum outro curso de bacharelado [...]"

P3: "[...] achamos por bem optar mesmo pelo tecnólogo, seguir o padrão, porque a gente tem um processo, via reitoria, que vai pra PROEN, um processo físico que é a escrita do projeto para ser aprovado ou não, a questão de infraestrutura, é feito tanto uma análise pedagógica quanto uma análise da infraestrutura, para ver se o campus pode ou não ofertar."

P4: "[...] o curso de tecnologia, considerando a situação atual do campus, considerando as demandas que curso exigia, era o melhor curso que o campus poderia ofertar."

Conforme o Parecer 136/2012, o profissional formado pelo bacharelado em Ciência da Computação possui uma visão bem abrangente, já que é apto a desenvolver toda a ciência e a tecnologia inerente a Computação, enquanto que o profissional formado pelo tecnólogo em Informática tem uma formação voltada mais para a prática no mercado de trabalho:

\footnotetext{
“[...] o tecnólogo [...] deverá receber uma sólida formação científica, com espectro de atuação mais específico e que lhe proporcione uma compreensão teórica e prática das atividades que irá executar, tornando-o apto a desenvolver, de forma plena, uma determinada área profissional. Enquanto os bacharéis são preparados para a concepção, com mais ênfase na Ciência, com atividades mais abrangentes, o Tecnólogo tem uma formação mais focada na gestão de processos de produção de bens e serviços." (JUCÁ; OLIVEIRA e SOUZA, 2010, p. 2-3)
}

Nesse contexto, cabe ressaltar que de acordo com a lei 11.892, de 29/12/2008 que instituiu a Rede Federal de Educação Profissional, Científica e Tecnológica, o Instituto Federal do Paraná tem como objetivo ofertar a educação profissional e tecnológica, dando margem para que o curso superior na modalidade tecnólogo fosse prioritário em relação ao bacharelado. 
Assim, o tecnólogo em informática se sobressaiu em relação ao bacharelado amparandose em todos os aspectos legais evidenciados que exigem que tais condições do IFPR - Campus Irati sejam cumpridas.

\section{CONSIDERAÇÕES FINAIS}

A análise dos argumentos que sustentaram a concepção do curso superior de Tecnologia em Análise e Desenvolvimento de Sistemas, nos mostrou a possibilidade de verticalização do eixo de Recursos Naturais com o curso superior em Agronomia, por exemplo. Observando o arranjo produtivo local, esse eixo parece se destacar em relação ao eixo de Informação e Comunicação. Tal reflexão nos remete a pensar nos aspectos subjetivos da abertura desse curso, que vão além daquilo que foi explicitado. Se relacionam inclusive com a postura dos outros professores na possibilidade de outros cursos, já que a iniciativa em termos de verticalização partiu dos docentes de informática desde a época da concepção ensino médio integrado, o que possibilitou uma consolidação desse eixo antecipadamente.

Ao investigar a concepção do curso pudemos vislumbrar a valorização da expectativa de crescimento pela indução regional. Resgatando tal pressuposto nos colocamos na busca por fomentar tal desenvolvimento, onde futuras pesquisas podem nos apontar para os reflexos da presença do curso na cidade de Irati, para as possibilidades de atuação dos egressos, bem como para as possibilidades de crescimento e consolidação do curso frente as necessidades do mercado de trabalho.

Os resultados dessa pesquisa nos mostraram que a verticalização do eixo de Recursos Naturais para um curso superior em Agronomia, por exemplo, seria favorecida pelo arranjo produtivo local, mas encontra nos aspectos legais uma barreira muito grande, uma vez que questões relacionadas a infraestrutura física do campus com salas de aulas, laboratórios e terrenos para as aulas práticas são de fundamental importância para a abertura de vagas para um curso superior. Com base nisso, o eixo de Informação e Comunicação já tinha uma estrutura mínima com a oferta do ensino médio integrado ao ensino técnico. Mesmo que o campus já tivesse ofertando a Agroecologia, a estrutura física para um curso superior na área tem mais exigências. Além disso, o corpo docente reduzido para esta área em comparação com os docentes de informática do Campus Irati também foi um fator determinante, já que havia um número maior de profissionais da informática que pudesse suprir uma demanda imediata de um curso superior.

Tal demanda imediata estava relacionado a necessidade de verticalização pautada nos aspectos legais ressaltados pela lei 11.892, de 29/12/2008 que instituiu a Rede Federal de Educação Profissional, Científica e Tecnológica. Com esta lei, o Instituto Federal do Paraná como um todo tem uma porcentagem mínima de vagas a serem ofertadas nas diversas modalidades de ensino, sendo a licenciatura e o tecnólogo prioritários.

Apesar de que legalmente os percentuais de oferta em cada modalidade seja a nível de IFPR, pela compreensão da reitoria, naquele momento isso deveria se dar por campus. No momento de autorização para abertura do curso firmou-se o compromisso de que o campus Irati apresentaria como próxima proposta um curso de licenciatura. O curso de licenciatura em química está com PPC escrito, com professores contatados, mas agora esbarra na questão de estrutura física para poder funcionar. Diante disso voltamos nossa atenção para a pertinência do argumento 
relativa a estrutura do campus Irati como um fator importante, tendo em vista a necessidade de ampliação dos cursos e da verticalização para consolidação e expansão do campus Irati.

Enquanto perspectiva futura para o campus é possível perceber o estágio de verticalização entre os eixos provocada pela abertura do curso superior. As demandas do curso já em andamento permitiram a contratação de professores e um investimento ainda maior na infraestrutura. $O$ efeito de fortalecimento do eixo de Recursos Naturais está em andamento, sendo que este ainda está num estágio anterior de desenvolvimento do que o eixo de Informação e Comunicação.

Entretanto nos cabe refletir, e se a opção naquele momento tivesse sido pela verticalização do eixo de recursos naturais? Quais caminhos teríamos percorrido para a conquista da infraestrutura? Quais resultados enquanto relação com a comunidade local teriam sido alcançados? Não nos interessa nesse momento pensar em arrependimentos, pelo contrário, a reflexão se mostra permanente no sentido de motivar novos projetos que beneficiem o campus e a comunidade local.

Diante de todos os argumentos levantados pelos discursos, concluímos que a concepção do curso superior de Tecnologia em Análise e Desenvolvimento de Sistemas foi um processo natural de amadurecimento do eixo temático naquele momento, dado todas as condições do campus, mas em relação as características regionais o que vislumbramos foi a expectativa de interferir ou mesmo alterar o arranjo produtivo local.

A partir dos resultados aqui obtidos, voltamos nosso olhar para a relevância do argumento da indução regional e desse modo, um horizonte que se abre é seguir o caminho da pesquisa nos questionando como isso está sendo conduzido no município, ou como poderia ser conduzido, tendo como foco a consolidação do curso e o cumprimento da meta do IFPR de promover o desenvolvimento regional.

Não temos como objetivo finalizar a discussão, o que pretendemos é fomentar o debate no fortalecimento da educação pública e do desenvolvimento regional.

\section{REFERÊNCIAS}

1. ASSOCIAÇÃO DE MUNICÍPIOS DA REGIÃO CENTRO DO PARANÁ. Histórico. Disponível em: < http://www.amcespar.com.br/pag.asp?id=69> Acesso em: 14 set. 2016.

2. BRASIL. Lei n. 11.892 , de 29 de dezembro de 2008. Institui a Rede Federal de Educação Profissional, Científica e Tecnológica, cria os Institutos Federais de Educação, Ciência e Tecnologia e dá outras providências. Brasília, DF, 30 de dez. 2008. Disponível em: <http://www.planalto.gov.br/ccivil_03/_ato2007-2010/2008/lei/l11892.htm>. Acesso em: 19 jun. 2016.

3.

Lei n. 5.773, de 9 de maio de 2006. Dispõe sobre o exercício das funções de regulação, supervisão e avaliação de instituições de educação superior e cursos superiores de graduação e sequenciais no sistema federal de ensino. Brasília, DF, 9 de mai. 2006. Disponível em: < http://www2.mec.gov.br/sapiens/portarias/dec5773.htm>. Acesso em: 19 jun. 2016.

4. Resolução CNE/CES n. 2/2007. Dispõe sobre carga horária mínima e procedimentos relativos à integralização e duração dos cursos de graduação, bacharelados, na modalidade presencial. Brasília, DF, 18 de jun. 2007. Disponível em: < 
http://portal.mec.gov.br/cne/arquivos/pdf/2007/rces002_07.pdf>. Acesso em: 19 jun. 2016.

5. _. Parecer CNE/CES n. 136/2012. Diretrizes Curriculares Nacionais para os cursos de graduação em Computação. Brasília, DF, 9 de mar. 2012. Disponível em: < http://portal.mec.gov.br/index.php?option=com_docman\&view=download\&alias=11205pces136-11-pdf\&Itemid=30192>. Acesso em: 19 jun. 2016.

6. MINISTÉRIO DA EDUCAÇÃO E CULTURA. Catálogo Nacional dos Cursos Superiores de Tecnologia. $2010 . \quad$ Disponível em: http://portal.mec.gov.br/index.php?option=com_docman\&view=download\&alias=44501cncst-2016-3edc-pdf\&category_slug=junho-2016-pdf\&Itemid=30192>. Acesso em: 19 ago. 2016.

7. IPARDES. Caderno estatístico do Município de Irati. Curitiba: IPARDES, 2016. Disponível em: <http://www.ipardes.gov.br/cadernos/MontaCadPdf1.php?Municipio=84500\&btOk=ok>. Acesso em: 14 set. 2016.

8. INSTITUTO FEDERAL DO PARANÁ. Projeto Político de Curso: Tecnologia em Análise e Desenvolvimento de Sistemas, Campus Irati, 2014.

9. IRATI, Prefeitura Municipal de. Plano Diretor Municipal de Irati. Irati, 2010. Disponível em: <http://www.irati.pr.gov.br/uploads/pagina/arquivos/PDM-IRATI-VOLUME-1-

DEFINITIVO.pdf>. Acesso em: 14 set. 2016.

10. JUCÁ, Mario Cesar, OLIVEIRA, Paulo Jorge, SOUZA, Romildo José de. Cursos Superiores Tecnológicos: um avanço da educação superior no Brasil. In: X Colóquio Internacional de Gestión Universitaria en América del Sur, 2010. Mar del Plata. Anais...Mar del Plata: [s. n.]. $11 p$.

11. MARTINS, Talita Cristiane, SOUZA, Solange de Cassia I de, MAIA, Katy. A importância dos arranjos produtivos locais (APLs) de confecções do norte e noroeste do Paraná para o mercado de trabalho local. In: V Encontro de Economia Catarinense, 2011. Florianópolis. Anais... Florianópolis: [s. n.]. 20 p.

12. PAULO, Rosa Monteiro, AMARAL, Carmen Lúcia Costa, SANTIAGO, Rosemary Aparecida. A pesquisa na perspectiva fenomenológica: explicitando uma possibilidade de compreensão do ser-professor de matemática. Revista Brasileira de Pesquisa em Educação em Ciências Vol. 10 N 3. São Paulo: 2010.

13. ROJAS, Jucimara, FONSECA, Regina Baruki, SOUZA, Rosana Sandri E. de. Fenomenologia e rigor na pesquisa educacional: a experiência da UFMS. In: IV Seminário Internacional de Pesquisa e Estudos Qualitativos, 2010, São Bernardo do Campo. Anais. São Bernardo do Campo: Editora SE\&PQ - Co-editora UMESP, v. 1, 2010, p. 1-10. Disponível em: <www.sepq.org.br/IVsipeq/anais/artigos/80.pdf>. Acesso em: 30 ago. 2016.

14. SILVA, Caetana Juracy Resende (Org.). Institutos Federais lei 11.892, de 29/12/2008: Comentários e Reflexões. Brasília, DF, Editora do IFRN, 2009. Disponível em: $<$ http://www2.ifam.edu.br/instituicao/missao-evisao/LEIDECRIAODOSINSTITUTOSFEDERAISDEEDUCACAOCIENCIAETECNOLOGIA.pdf>. Acesso em: 08 ago. 2016.

15. SORGI, Fernando Antonio. Desenvolvimento econômico regional: um estudo do norte pioneiro do Paraná - Microrregião de Cornélio Procópio. 106 f. Dissertação (Mestrado) - 
Universidade Federal do Paraná. Curitiba: 2009. Disponível em: $<$ http://www.economia.ufpr.br/Dissertacoes\%20Mestrado/156\%20-

\%20FERNANDO\%20SORGI.pdf>. Acesso em: 06 set. 2016.

16. WEISZFLOG, Walter. Dicionário Online - Dicionários Michaelis - UOL. Editora Melhoramentos Ltda: 2009. Disponível em: <http://michaelis.uol.com.br/moderno/portugues/index.php>. Acesso em: 15 mai. 2016. 